\title{
Efficient Design of LOE Pass FIR Filter by Hamming, Kaiser and Blackman Window Techniques
}

\author{
Yogesh Chandrosha ${ }^{1}$, Nirmala Maheshwari ${ }^{2}$, Pranay Kumar Rahi ${ }^{3}$ \\ B.E. Scholar, Department of Electrical and Electronics Engineering, Institute of Technology, Korba ${ }^{1,2}$ \\ Assistant Professor, Department of Electrical and Electronics Engineering, Institute of Technology, Korba ${ }^{3}$
}

\begin{abstract}
Digital filtering plays a significant role in the world of technology. This paper deals with the design of finite impulse response digital filter using window techniques. Here various windows are compared and demonstration of the best window is done, which is the one with minimum side lobes. This paper presents the importance of filter in signal processing. Digital filter are two type 1. FIR and 2. IIR. These are various methods for filter designing. This paper discuss the window method low pass fir filter designing Hamming, Kaiser and Blackman window function methods are presented. Design of FIR filter is done in MATLAB by FDATOOL low pass filter is designed with sampling frequency $48000 \mathrm{~Hz}$ and cut-off frequency $10000 \mathrm{~Hz}$ magnitude, phase impulse, step response and pole, zero plot. We found that filter designing by window method is easy and fast.
\end{abstract}

Index Terms: FIR, Digital filter, DSP, low pass filter, window function, MATLAB, FDATOOL in MATLAB, Hamming window, Kaiser Window and Blackman Window techniques.

\section{INTRODUCTION}

Digital signal processing is an area of science and FIR filters are broadly used in various fields, such as long engineering that has developed rapidly over the past 40 distance communication, image processing applications years. This rapid development is a result of the significant etc advances in digital computer technology and integrated circuit fabrication [1]. It is the network which changes the amplitude, frequency, phase frequency characteristics of the signal in desired manner. Digital filters have characteristics such as linear phase response. If we compare digital filter with analog. Filter they are preferred in number of application like speech processing, image processing and data compression[2].

\subsection{BASIC PRINCIPLE OF FIR WINDOW TECHNIQUE}

The filter is used to describe a linear time - invariant system used to perform spectral shaping or frequencyselective filtering. Filter is used in digital signal processing is widely used in a number of ways, such as removal of undesirable noise from desired signals, spectral shaping such as equalization of communication channels, signal detection in radar, sonar and communications, and for performing analysis of the spectra of a variety of signals[3]. There are two major types of digital filters are:

1) Infinite Impulse response (IIR) filters 2) Finite Impulse response (FIR) filters. Infinite Impulse Response (IIR) digital filter has the problems of phase non-linearity. Therefore it is a low order filter which becomes highly unstable. Due to these factors, the FIR filter can be used to design a linear phase digital filter which is convenient for image processing and data transmission applications. The
The system function of FIR filter is given below:

$$
\mathrm{H}(\mathrm{z})=\sum L N-=10 h[n] z-1
$$

where, $\mathrm{L}$ is the length of the filter, and $\mathrm{h}[\mathrm{n}]$ is the impulse response[4].

\section{WINDOW AND THEIR EQUATIONS}

Several window function have been proposed. Listed below are some of the most common.

Hamming window

Kaiser window

Blackman window

To reduce the oscillation in fourier series method, the fourier coefficient are modified by multiplying the infinite impulse response by a finite weighing sequence $\omega(\mathrm{n})$ called a window. Windows are characterize by the main lobe width which is the bandwidth between first negative and first positive zero crossing and by their ripple ratio. The main lobe far as possible in the main lobe and the energy in the side lobe should be as low as possible [5].

FIR filters are employed in filtering problems where linear phase characteristics within the passband of the filter are required. If this is not required, either an IIR or an FIR filter may be employed. An IIR filter has lesser number of 
side lobes in the stopband that an FIR filters with the same number of parameters. For this reason, if some phase distortion is tolerable, an IIR filter is preferable. Also, the implementation of an IIR involves fewer parameters, less memory requirements and lower computational complexity [6].

\subsection{HAMMING WINDOW}

Richard W. hamming observed that the side lobes of the rectangular and HANNING windows are phase reversed relative to each other, so a linear combination of the two would tend to cause them to cancel each other. He searched for the linear combination that minimized the maximum side lobe amplitude and came up with the following formulation, which represents a raised cosine on a rectangular pedestal[7]

$$
\begin{cases}0.54-0.46 \cos \left(\frac{2 \pi n}{M}\right), & 0 \leq n \leq M \\ 0, & \text { otherwise } \omega[\mathrm{n}]=\end{cases}
$$

\subsection{KAISER WINDOW}

The width of the main lobe is inversely proportional to the length of the filter. The attenuation in the side lobe is, however, independent of the length and is function of the type of the window. Therefore the length of the filter must be increased considerably to reduce the main lobe width and to achieve the desired transition band.

Kaiser has chosen a class of window having properties closely approximating those of the prolate spheroidal wave functions. [8]

\subsection{BLACKMAN WINDOW}

Blackman windows are defined as: By common convention, the unqualified term Blackman window refers to $\alpha=0.16$, as this most closely approximates the "exact Blackman", with a $0=7938 / 18608 \approx 0.42659$, a1 $=$ $9240 / 18608 \approx 0.49656$, and $\mathrm{a} 2=1430 / 18608 \approx 0.076849$.

These exact values place zeros at the third and fourth side lobes[8].

$$
\mathrm{W}(\mathrm{n})=\mathrm{a} 0-\mathrm{a} 1 \cos (2 n \pi / N-1)+\mathrm{a} 2 \cos (4 n \pi / N-1)
$$

Where;

$\mathrm{a} 0=1-\alpha / 2$

$\mathrm{a} 1=1 / 2$

$\mathrm{a} 2=\alpha / 2$

\section{SIMULATION AND RESULT}

Table 1. Parameter specification

\begin{tabular}{|l|l|}
\hline PARAMETER & VALUES \\
\hline Sampling Frequency $\left(\mathrm{F}_{\mathrm{s}}\right)$ & 48000 \\
\hline Cut-off Frequency $\left(\mathrm{F}_{\mathrm{c}}\right)$ & 10000 \\
\hline Order $(\mathrm{N})$ & 30 \\
\hline
\end{tabular}

Table -2 . Frequency and magnitude

\begin{tabular}{|l|l|l|l|}
\hline frequency & Hamming & Kaiser & Blackman \\
\hline $0.1 \pi$ & -0.038 & 0.182 & -0.001 \\
\hline $0.2 \pi$ & -0.001 & 0.657 & 1.685 \\
\hline $0.3 \pi$ & -0.018 & -2.738 & 0.000 \\
\hline $0.4 \pi$ & -0.04 & -4.529 & -0.001 \\
\hline $0.5 \pi$ & -0.015 & -6.213 & -0.003 \\
\hline $0.6 \pi$ & -0.05 & -7.789 & -0.140 \\
\hline $0.7 \pi$ & -0.029 & $-9 . .440$ & -0.501 \\
\hline $0.8 \pi$ & -0.189 & -10.757 & -2.195 \\
\hline $0.9 \pi$ & -2.064 & -12.077 & -2.195 \\
\hline$\pi$ & -4.711 & -14.398 & -6.754 \\
\hline
\end{tabular}

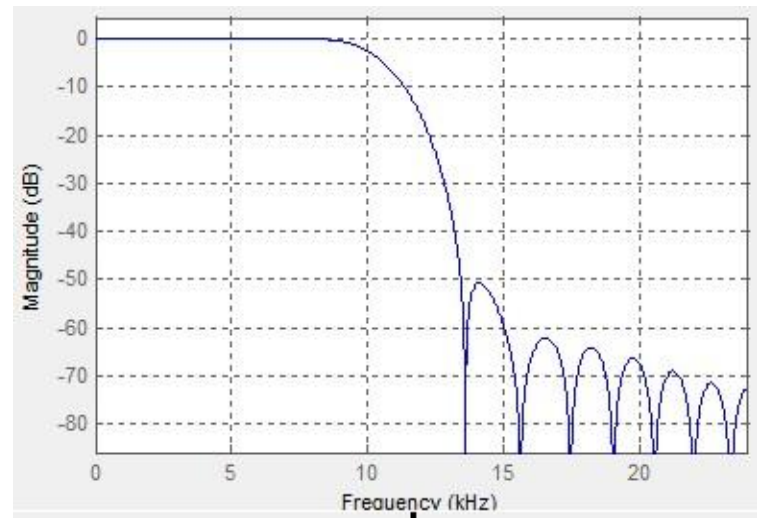

Figure - 1. Magnitude response of hamming window

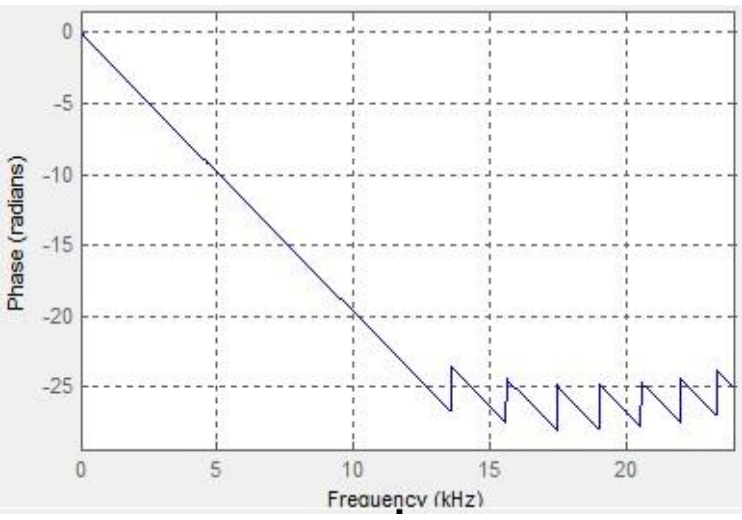

Figure -2 . Phase response of hamming window

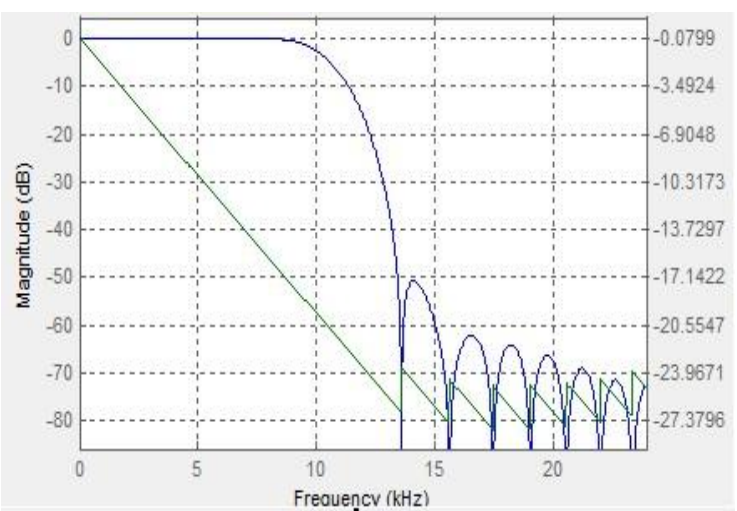

Figure -3 . Magnitude and phase response of hamming window 


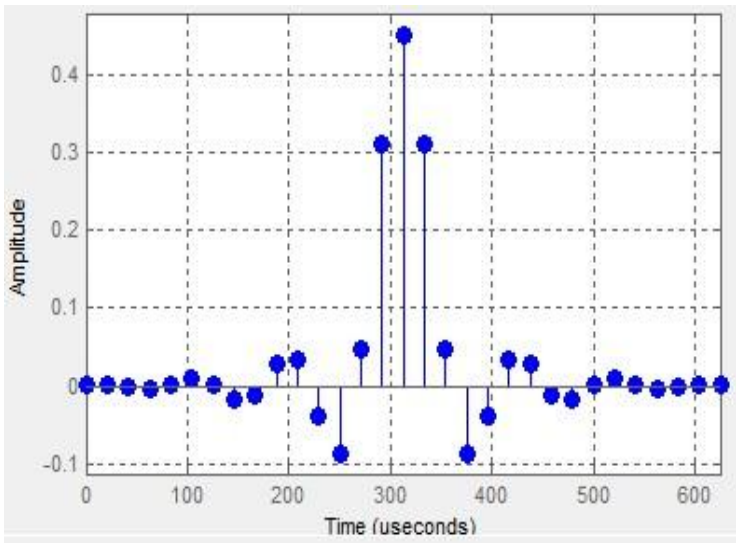

Figure - 4. Impulse response of hamming window

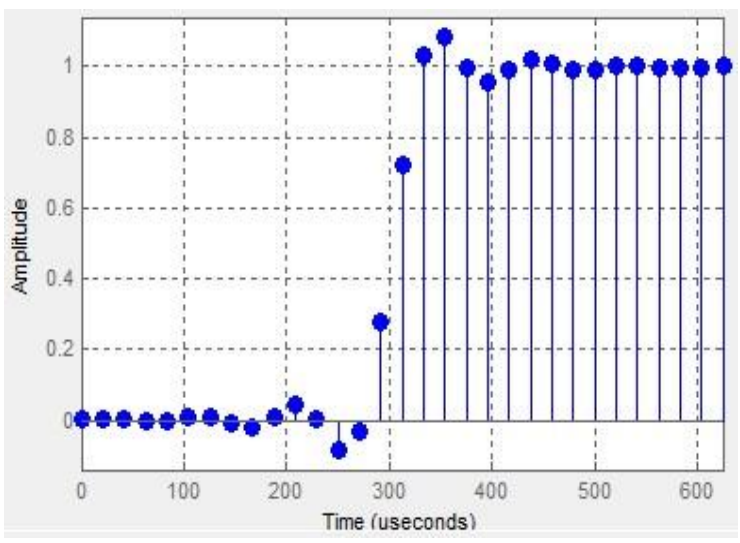

Figure -5 . Step response of hamming window.

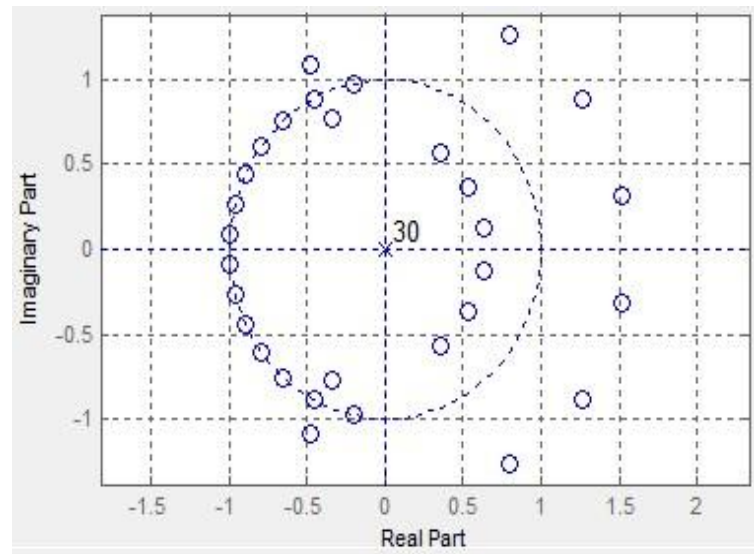

Figure -6 . Poles and zeros plot of hamming window.

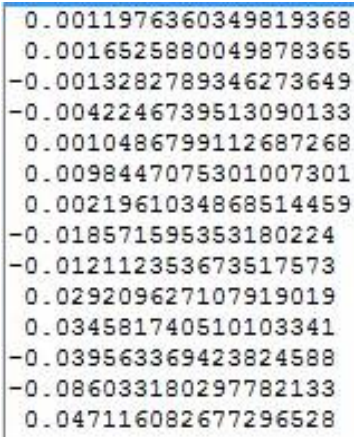

Figure -7 . Filter coefficient of hamming window.

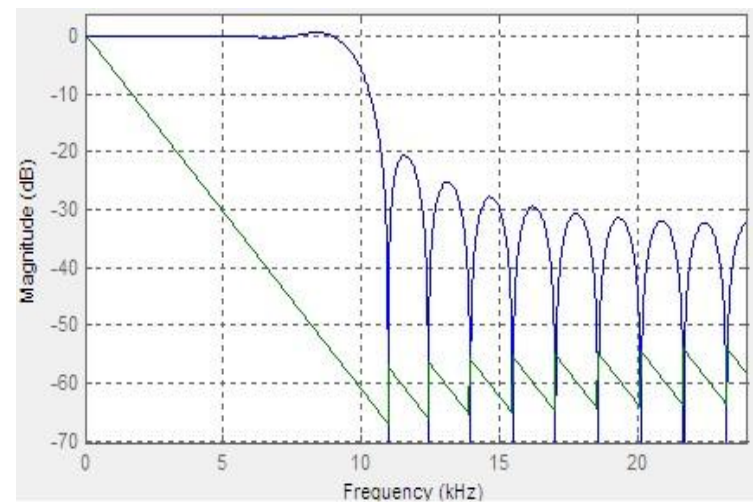

Figure -8 . Magnitude and phase response of Kaiser window.

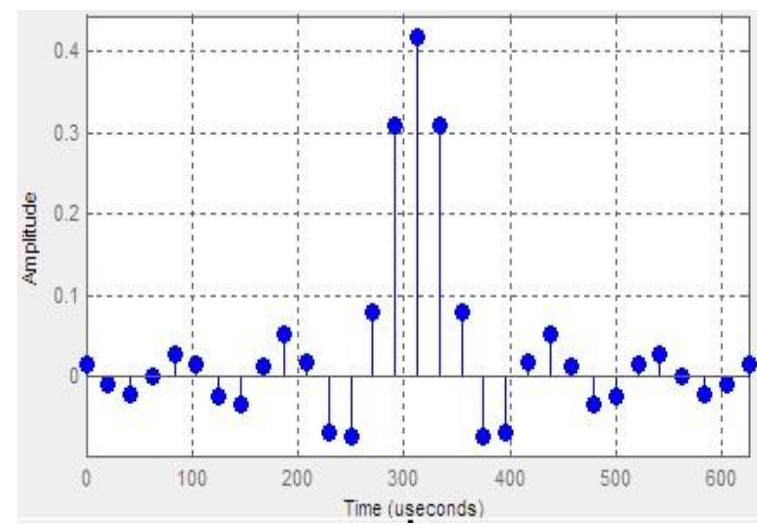

Figure -9. Impulse response of Kaiser window.

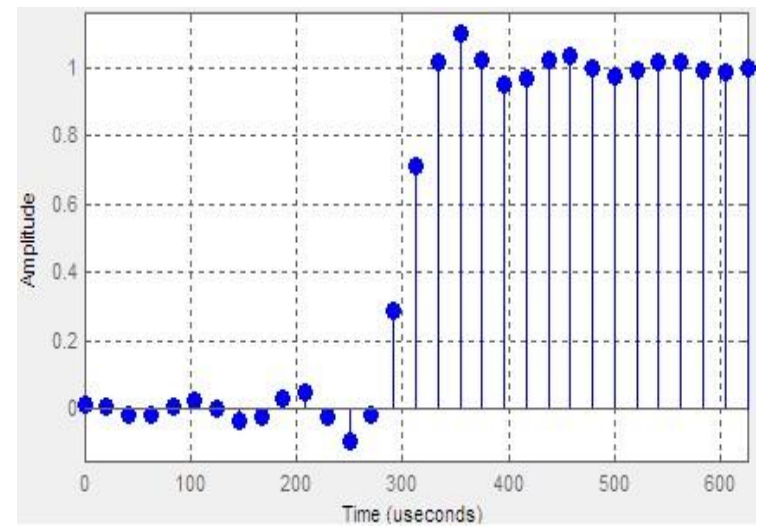

Figure - 10. Step response of Kaiser window.

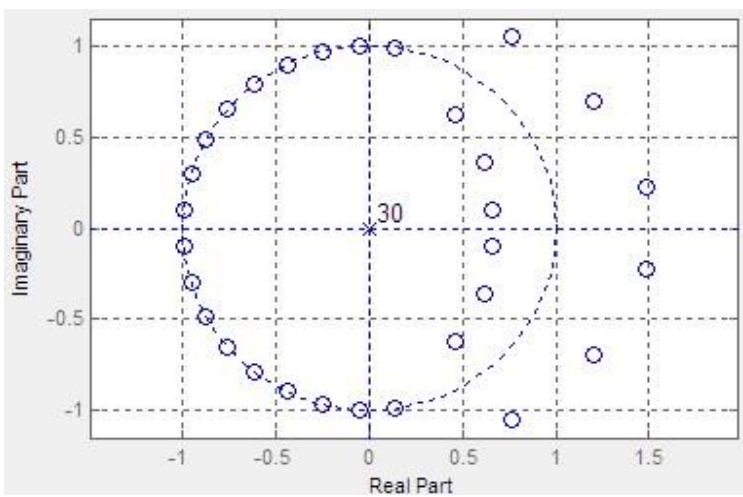

Figure - 11.. poles and zeros plot of Kaiser window. 
Vol. 6, Issue 3, March 2017

\begin{tabular}{|l|}
\hline 0.014188645694526878 \\
-0.010836290334662895 \\
-0.022713142557357544 \\
0.00000000000000015705942919470821 \\
0.027199136290257678 \\
0.015576431137705148 \\
-0.024603153780010763 \\
-0.034056304756821497 \\
0.011679481471003504 \\
0.052832839657263514 \\
0.016457878007063019 \\
-0.069004001408071294 \\
-0.075264098346048608 \\
0.079937344538486318 \\
0.3091040224421096 \\
0.41900242388911402 \\
\hline
\end{tabular}

figure -12 . Filter coefficient of Kaiser window.

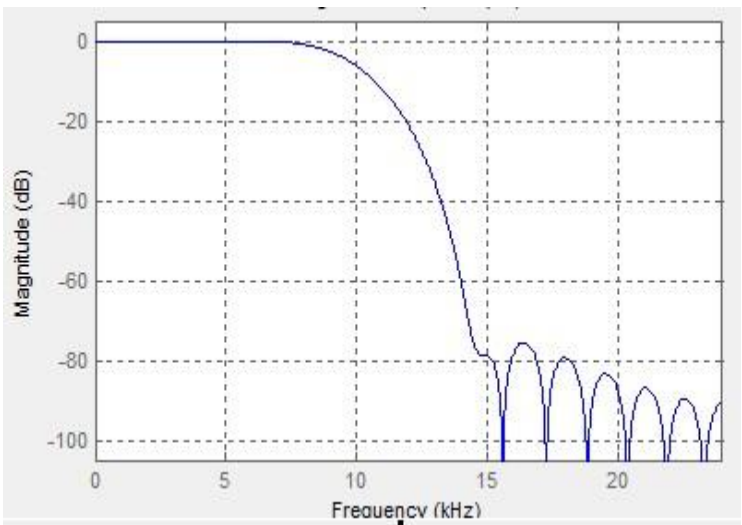

Figure - 13. Magnitude response of blackman window.

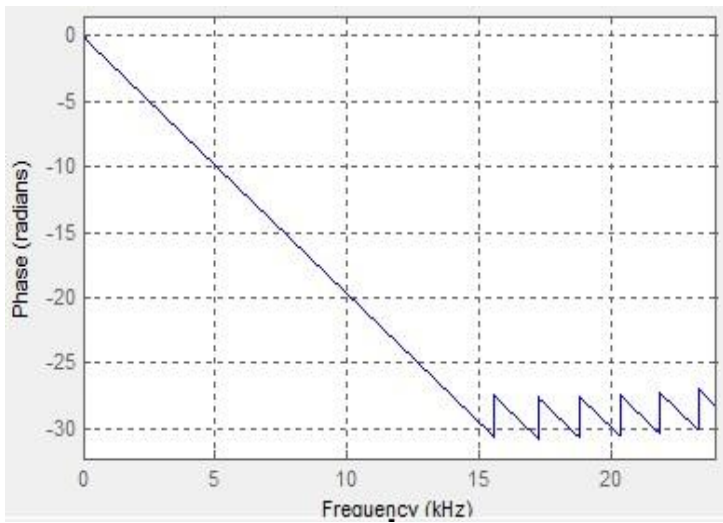

Figure -14 . Phase response of blackman window.

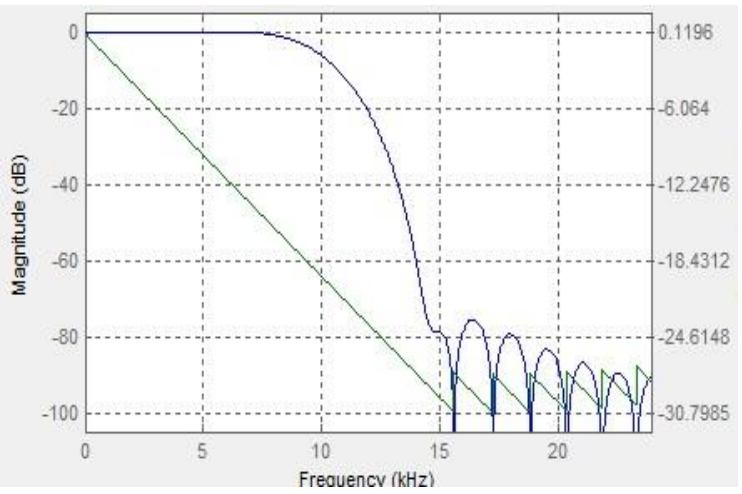

Figure - 15. Magnitude and phase response of blackman window.

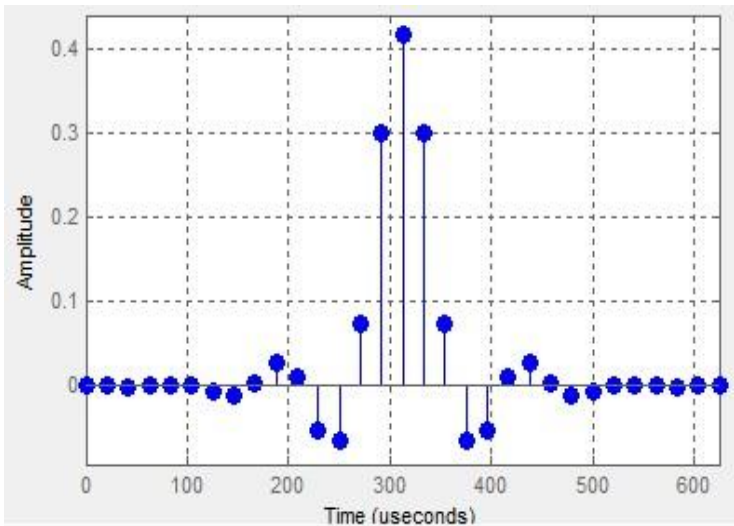

Figure - 16. Impulse response of blackman window.

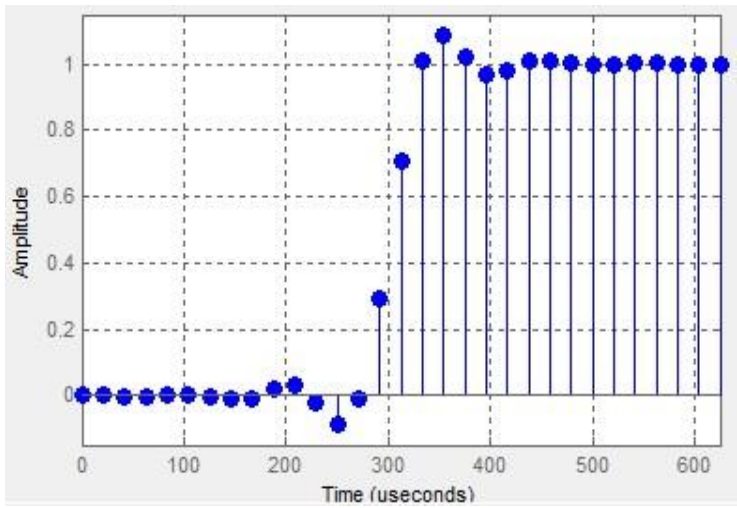

Figure - 17. Step response of blackman window.

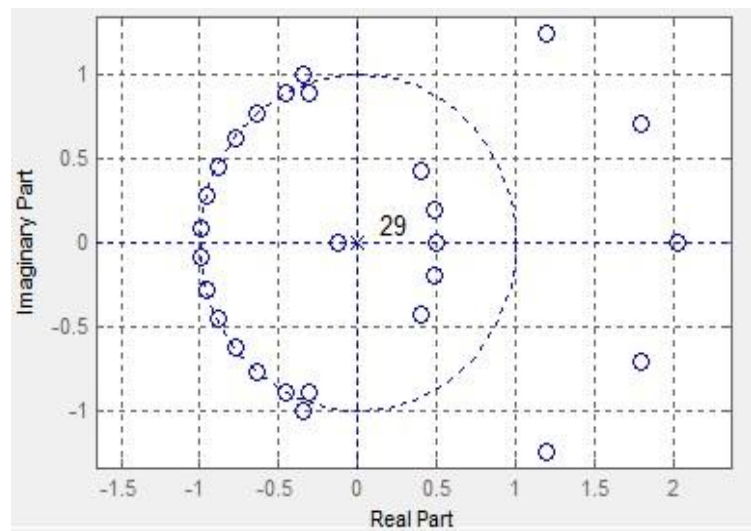

Figure -18 . Poles and zeros plot of blackman window

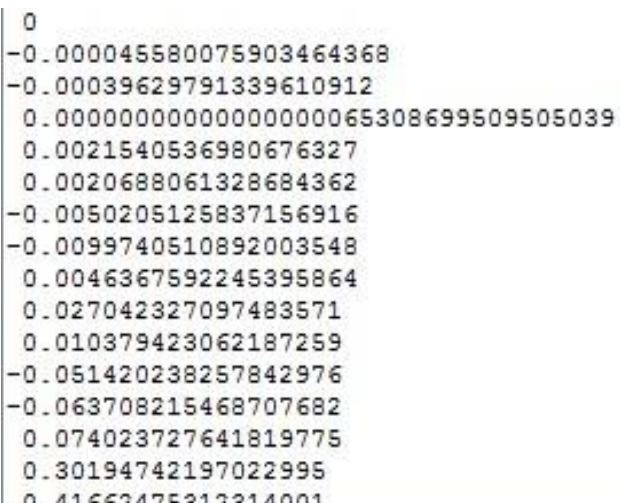

0.41662475312314001

Figure -19 . Filter coefficient of blackman window. 


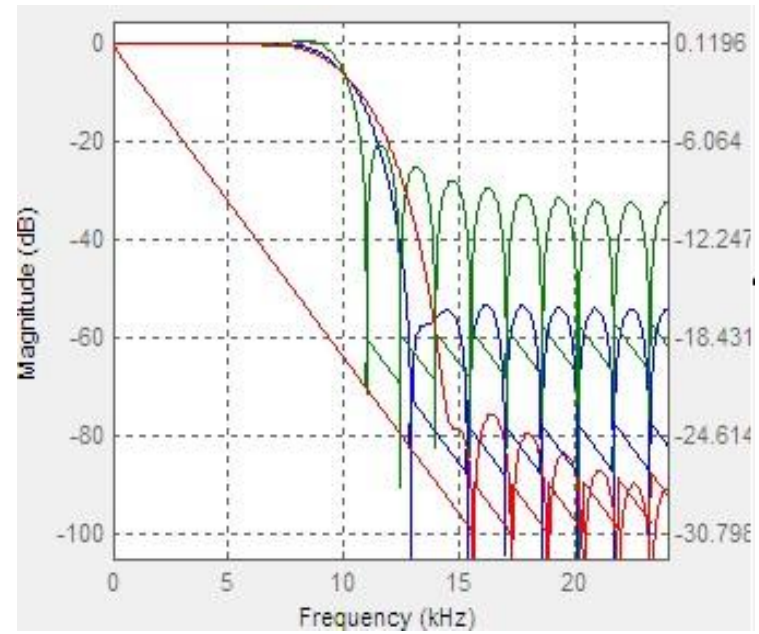

Figure - 20. Magnitude and phase response comparison of hamming, Kaiser and blackman window

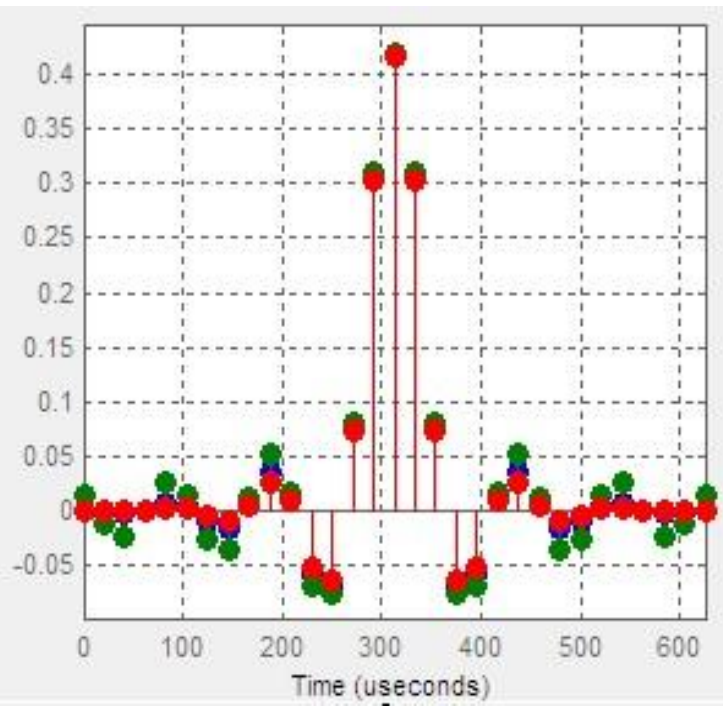

Figure - 21. Impulse response of hamming, Kaiser and blackman window

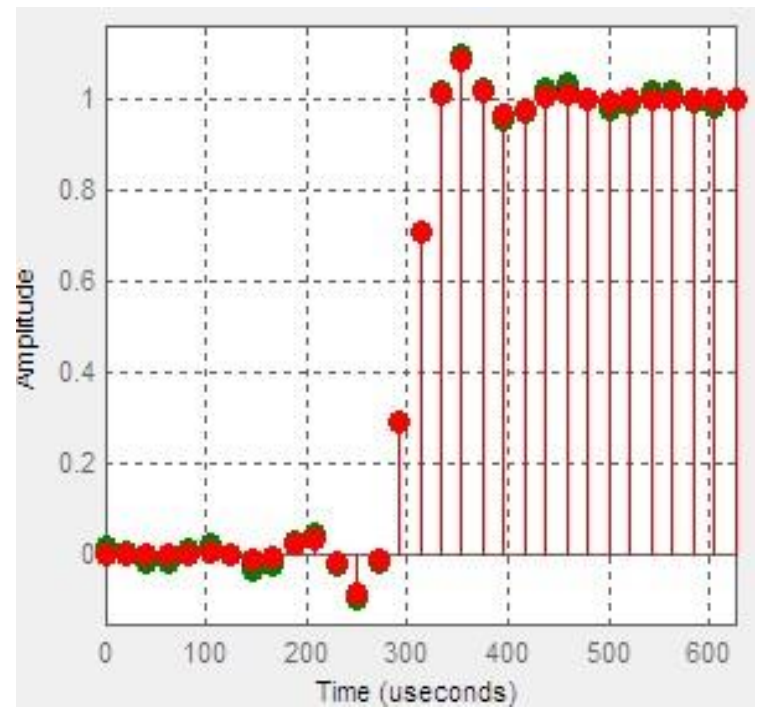

Figure - 22. Step comparison of hamming, Kaiser and blackman window

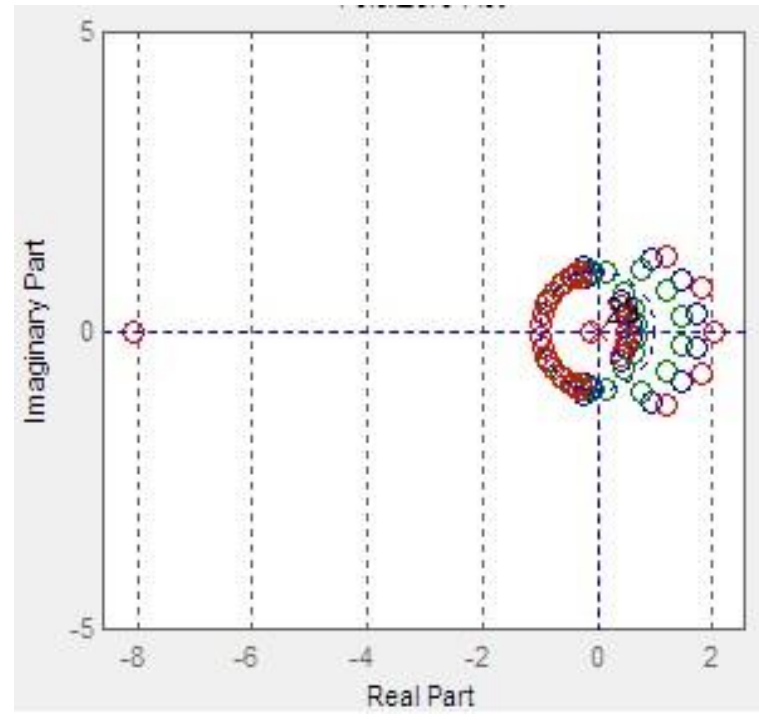

Figure - 23. Poles and zeros plot comparison of hamming, Kaiser and blackman window.

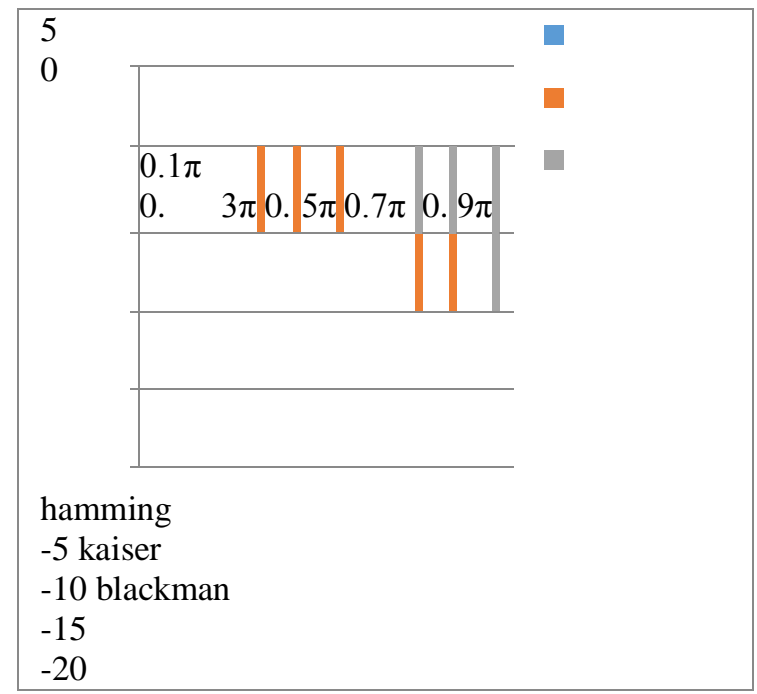

Figure - 24. Magnitude and frequency plot of hamming, Kaiser and blackman window.

\section{CONCLUSION}

In this research paper low pass FIR filter has been design using MATLAB hamming, blackman and kaiser window technique. It concludes by comparative value of both magnitude and phase response of the filter using above the technique at same frequency.

i.e $\mathrm{F}_{\mathrm{s}}=48000 \mathrm{~Hz}$

$\mathrm{Fc}=10000 \mathrm{~Hz}$

In blackman windowing technique the unwanted signals are not present after the cut-off frequency, but this technique also cuts the wanted signal. The result show that the filter design using modified window function has a small main lobe width and sharp transition band compared to hamming, blackman and Kaiser window function. The major advantages of window technique is its simplicity 
and easy to understand using FDATOOL in MATLAB, we can design Digital filter very easily.

\section{REFERENCES}

[1] John G. Proakis, Dimitris G. Manolakis, "Digital Signal Processing Principles, Algorithms and Applications", PEAESON, 4th Edition, 2008.

[2] Divya Goyal, Ritesh Goel, "Review of Low-Pass FIR Filter Design Using Window Method", International Journal of Advanced Research in Electronics and Communication Engineering (IJARECE) Volume 4, Issue 7, July 2015.

[3] Mohd. Shariq Mahoob \& Rajesh Mehra, "Design of Low Pass FIR Filter Using Hamming,

[4] Blackman-Harris and Taylor Window" International Journal of Advance Research In Science And Engineering IJARSE, Vol. No.3, Issue No.11, November 2014.

[5] S. M. Shamsul Alam and Md. Tariq Hasan, "Performance Analysis of FIR Filter Design by Using Optimal, Blackman Window and Frequency Sampling Methods", International Journal of Electrical \& Computer Sciences (IJECS-IJENS) Vol:10, No:01, February 2010, pp. 9-14.

[6] Pranay Kumar Rahi , Pramod Yadav, Shankarlal Sahu, Vijendra Prajapati, "Designing a Low Pass FIR Filter by Using Rectangular and Taylor Window", International Journal of Innovative Science, Engineering \& Technology, Vol. 3 Issue 8, August 2016.

[7] S Salivahanan and C Ghanapriya, "Digital Signal Processing", Tata Mc Graw -Hill, $2^{\text {nd }}$ Edition, pp. 1, 430-469, 2010.

[8] Carnegie Mellon, "Notes on FIR Filter Design Using Window Function", Siganls and System (18396).

[9] Using Window Function", Siganls and System, Volume 18, 396.

\section{BIOGRAPHIES}

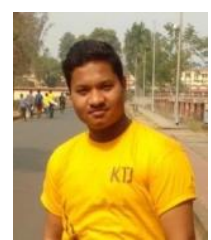

Yogesh Chandrosha persuing bachelor of engineering in electrical and electronics engineering in 6th semester from institute of technology korba,Chhattisgarh Swami Vivekanand Technical

University, India.

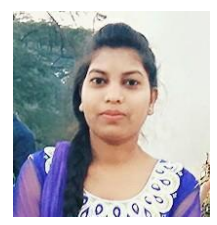

Nirmala Maheshwaripersuing bachelor of engineering in electrical and electronics engineering in 6th semester from institute of technology korba,Chhattisgarh Swami Vivekanand Technical

University, India.

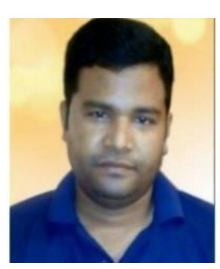

Pranay Kumar Rahireceived the bachelor of technology degree in Electronics and Telecommunication engineering collage, guru ghashid as university, bilaspur Chhattisgarh, india in 2004, and persuing master of engineering in electronics and communication engineering from national institute of technical teacher's training \& research, Punjab university, Chandigarh, india. Presently working as assistant professor in department of electrical and electronics engineering, institute of technology, korba Ch.hattisgarh since 2008. He has authored more than 40 research publications and published journal paper and research papers in the leading international and national journal. This primary research interest includes digital signal processing, VLSI design, control systems and digital electronics and logic design. 